Article

\title{
Evaluation of the Change in Undrained Shear Strength in Cohesive Soils due to Principal Stress Rotation Using an Artificial Neural Network
}

\author{
Grzegorz Wrzesiński ${ }^{1, *}$, Maria Jolanta Sulewska ${ }^{2}$ and Zbigniew Lechowicz ${ }^{1}$ \\ 1 Faculty of Civil and Environmental Engineering, Warsaw University of Life Sciences, \\ Nowoursynowska 159 St., 02-776 Warsaw, Poland; zbigniew_lechowicz@sggw.pl \\ 2 Faculty of Civil and Environmental Engineering, Bialystok University of Technology, Wiejska 45E St., \\ 15-351 Bialystok, Poland; m.sulewska@pb.edu.pl \\ * Correspondence: grzegorz_wrzesinski@sggw.pl; Tel.: +48-22-5935-210
}

Received: 24 March 2018; Accepted: 10 May 2018; Published: 14 May 2018

\begin{abstract}
This paper presents a method describing the application of artificial neural networks to evaluate the change in undrained shear strength in cohesive soils due to principal stress rotation. For analysis, the results of torsional shear hollow cylinder (TSHC) tests were used. An artificial neural network with an architecture of 7-6-1 was able to predict the real value of normalized undrained shear strength, $\tau_{f u} / \sigma_{v}^{\prime}$, based on soil type, over-consolidation ratio (OCR), plasticity index, $I_{P}$, and the angle of principal stress rotation, $\alpha$, with an average relative error of around $\pm 3 \%$, and a single maximum value of relative error around $6 \%$.
\end{abstract}

Keywords: artificial neural network analysis; cohesive soil; normalized undrained shear strength; principal stress rotation; torsional shear hollow cylinder test

\section{Introduction}

Undrained shear strength is one of the basic parameters that characterizing the mechanical properties of cohesive soils. The value of this parameter depends on soil type, consistency, stress state, history, and also depends on factors such as loading type and loading mode [1,2]. The loading of subsoil changes the stress state of the soil, and thereby causes principal stress rotation in comparison with the soil's initial state obtained during the sedimentation process [3]. Research performed in a torsional shear hollow cylinder apparatus (TSHCA), both on undisturbed and reconstituted cohesive soils, has shown that principal stress rotation has a significant impact on the value of undrained shear strength. Undrained shear strength had a major principal stress value in the $\sigma_{1}$ horizontal, which was about 0.70 of the value of that of the vertical $\sigma_{1}$, as previously observed in the literature [4-8]. Therefore, when determining the bearing capacity of the subsoil, changes resulting from this phenomenon should be taken into account. Test investigations that determine the impact of principal stress rotation on the undrained shear strength of subsoil are costly and time-consuming. Hence, other methods to evaluate the change in undrained shear strength are used.

The impact of principal stress rotation on undrained shear strength may be estimated using the relationship proposed by Bishop [9]:

$$
C_{u}=C_{u V} \cdot\left(1-a_{B} \cdot \sin ^{2} \theta\right) \cdot\left(1-b_{B} \cdot \sin ^{2} 2 \theta\right),
$$

where $C_{u V}$ is the undrained shear strength with a vertical direction of applied stress, $a_{B}$ and $b_{B}$ are empirical coefficients, and $\theta$ is the inclination of major principal stress with respect to the vertical axis. 
In the Bishop relationship, only undrained shear strength with a vertical direction of applied stress is determined in the tests, while the change in undrained shear strength depends on empirical parameters.

Kulhavy and Mayne [10] proposed a systematic framework to estimate normalized undrained shear strength as a function of normalized undrained shear strength, under an isotropically-consolidated undrained compression test with a strain rate equal to $1 \% / \mathrm{h}$ on normally-consolidated clay. The following dimensionless modifiers were also taken into account: test mode, over-consolidation ratio, strain rate. Ching and Phoon [11] constructed a multivariate probability distribution of undrained shear strength from various test procedures, based on a large clay database. This multivariate distribution provided an estimate of normalized undrained shear strength based on four factors: test mode, over-consolidation ratio, strain rate, and plasticity. Houlsby and Houlsby [12] performed a statistical fitting of undrained strength data using Bayesian statistical methods. The presented approach allowed the fitting of a design profile to a set of measurements of undrained shear strength.

Artificial neural networks (ANNs) are tools of information technology, often used in science and various fields of technology for modeling complex phenomena (e.g., [13-16]). ANNs are alternatively used for statistical analysis methods, as they are often more useful compared to traditional methods [17].

Reviews of the application of ANNs in civil engineering were presented by Adeli [18], Ghaboussi [19], and Rojas [20]. Waszczyszyn [21,22] presented applications of ANNs in various subjects: analysis of regression problems, hybrid computational systems, development of ANNs, Bayesian neural networks (BNNs), principal component analysis (PCA), and recurrent cascade neural networks (RCNNs). Rafiq et al. [23] provided guidelines and examples of engineering applications of three types of neural networks: multilayer perceptrons (MLPs), radial basis function (RBF) networks, and normalized RBF (NRBF) networks.

In geotechnical engineering, ANNs have been used to analyze many issues, as reviewed by Dihoru et al. [24], Pichler et al. [25], Rafiq et al. [23], Shahin et al. [26,27], Tian et al. [28], Sulewska [29], and Zhou et al. [30]. Constitutive modeling of soils in triaxial tests, based on neural networks, were carried out by Basheer [31], Ellis et al. [32], Fu et al. [33], Najjar and Huang [34], Penumadu and Zhao [35], and Sidarta and Ghaboussi [36]. Lee et al. [37] presented neural network models for evaluating unsaturated shear strength. The use of ANNs for the prediction of the lateral earth pressure ratio, $K_{0}$, based on a dilatometer test was shown by Das and Basudhar [38], and the prediction of undrained shear strength was shown by Byeon et al. [39] and Lee et al. [37]. However, artificial neural networks have not been applied to the evaluation of the change in undrained shear strength in cohesive soils due to principal stress rotation. For this purpose, a series of undrained shear strength tests in a torsional shear hollow cylinder apparatus, both on undisturbed and reconstituted cohesive soil samples, was carried out.

\section{Materials and Methods}

Laboratory tests to determine undrained shear strength were performed in the Water Center Laboratory at the Warsaw University of Life Sciences (SGGW) using the torsional shear hollow cylinder apparatus (Figure 1). Tests were carried out on undisturbed $(\mathrm{U})$ and reconstituted $(\mathrm{R})$ soil samples of clay $(\mathrm{Cl}(\mathrm{U}))$, sandy silty clay $(\operatorname{sasiCl}(\mathrm{U})$ and sasiCl$(\mathrm{R}))$, and clayey sand $(\mathrm{clSa}(\mathrm{R}))$. The clay samples had an over-consolidation ratio (OCR) of 3.5 and a plasticity index $I_{P}$ of $77.6 \%$. The samples of sandy silty clay had an OCR of 2.7 and an $I_{P}$ of $34.7 \%$, whereas the samples of clayey sand had an OCR of 8.0 and an $I_{P}$ of $10.5 \%$. The index properties of the tested soils are presented in Table 1 . The undrained shear strength was determined at angles of principal stress rotation, $\alpha$, equal to $0^{\circ}, 30^{\circ}, 45^{\circ}, 60^{\circ}$, and $90^{\circ}$ for clay and clayey sand, and equal to $0^{\circ}, 15^{\circ}, 30^{\circ}, 45^{\circ}, 60^{\circ}, 75^{\circ}$, and $90^{\circ}$ for sandy silty clay. Undisturbed soil samples were taken directly from the excavation site at the Copernicus Science Center station of the II underground line in Warsaw, while reconstituted samples were prepared in the laboratory using material from undisturbed samples, following their failure. 


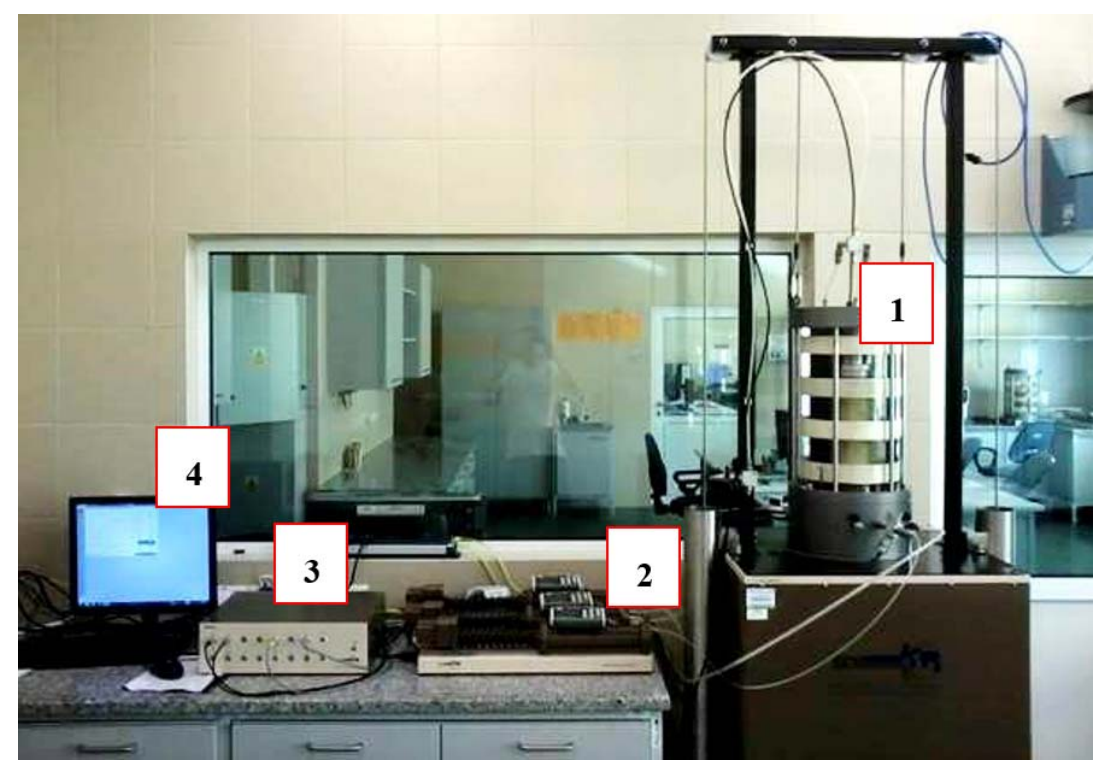

Figure 1. Torsional shear hollow cylinder apparatus (TSHCA) in the Water Center Laboratory at the Warsaw University of Life Sciences (SGGW). (1) TSHC apparatus cell, (2) pressure and volume controllers, (3) electronic measuring device, (4) computer.

Table 1. Index properties of the tested soils [40,41].

\begin{tabular}{|c|c|c|c|c|c|c|c|c|}
\hline \multirow{2}{*}{ Soil type [42] } & \multirow{2}{*}{$w_{L}(\%)$} & \multirow{2}{*}{$w_{P}(\%)$} & \multirow{2}{*}{$I_{L}(-)$} & \multirow{2}{*}{$I_{C}(-)$} & \multicolumn{4}{|c|}{ Fraction [43] (\%) } \\
\hline & & & & & Gr & Sa & Si & $\mathrm{Cl}$ \\
\hline $\mathrm{Cl}(\mathrm{U})$ & 112.9 & 35.3 & -0.06 & 1.06 & 0 & 5 & 36 & 59 \\
\hline $\begin{array}{l}\text { sasiCl(U) } \\
\text { sasiCl(R) }\end{array}$ & 59.0 & 24.3 & 0.13 & 0.87 & 0 & 21 & 50 & 29 \\
\hline $\mathrm{clSa}(\mathrm{R})$ & 19.4 & 8.7 & 0.75 & 0.25 & 0 & 70 & 19 & 11 \\
\hline
\end{tabular}

Notes: $w_{L}$-liquid limit, $w_{P}-$ plastic limit, $I_{L}$-liquidity index, $I_{C}$-consistency index. Gr-gravel, Sa—sand, Si-silt, $\mathrm{Cl}$-clay, $\mathrm{R}$-reconstituted, U-undisturbed.

The TSHC tests were performed on soil samples in the shape of a hollow cylinder (Figure 2). Tests, both on undisturbed and reconstituted soils, were performed in six consecutive stages: flushing, saturation, consolidation, change of the intermediate principal stress parameter, $b$, change of the angle of principal stress rotation, $\alpha$, and finally, shearing in undrained conditions. Parameter $b$ is defined as:

$$
b=\frac{\left(\sigma_{2}-\sigma_{3}\right)}{\left(\sigma_{1}-\sigma_{3}\right)}
$$

where $\sigma_{1}$ is the major principal stress, $\sigma_{2}$ is the intermediate principal stress, and $\sigma_{3}$ is the minor principal stress.

Flushing was carried out to remove air and gases from soil samples and tubes having the largest dimensions. Saturation of soil samples was performed using the back pressure method. This stage lasted until the value of Skempton's parameter, $B$, exceeded 0.95 . Next, anisotropic consolidation was performed. In the case of clay, the value of $K_{o}$ during the consolidation process was equal to 0.97 , whereas for sandy silty clay, $K_{o}$ was equal to 0.83 . After dissipation of excess pore water pressure, parameter $b$ was changed to 0.5 (Equation (1)) [44].

In the next step, the value of angle $\alpha$ was changed to the determined value in particular test. Finally, the process of sample shearing was carried out in the stress path, involving an increase in deviator stress, $q$, and a constant value of total mean stress, $p$. During the entire shearing process of the 
soil samples, values of parameter $b$ and angle $\alpha$ were kept constant. An example of the soil samples after the TSHC tests is shown in Figure 3.
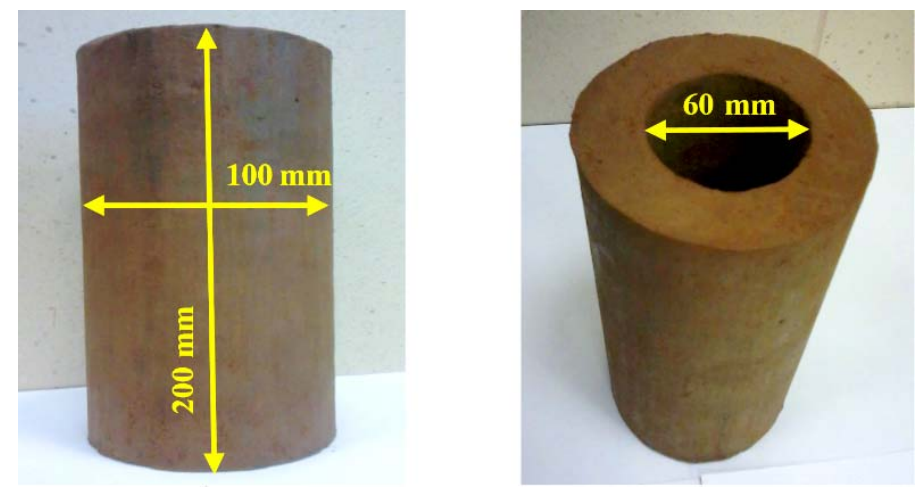

Figure 2. An example of a soil sample in the shape of a hollow cylinder.
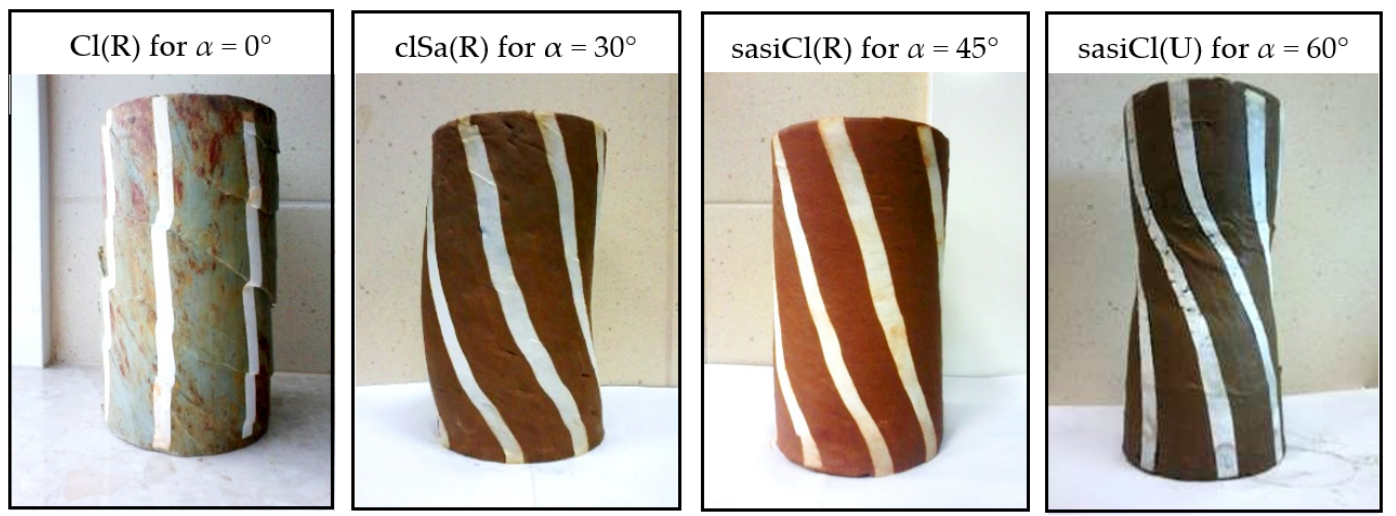

Figure 3. Selected soil samples after the TSHC tests.

\section{Results}

The TSHC tests allowed the values of undrained shear strength to be obtained at selected angles of principal stress rotation for undisturbed clay, undisturbed and reconstituted sandy silty clay, as well as reconstituted clayey sand (Table 2). To determine these parameters, the maximum deviator stress was used as the failure criterion. All obtained values of undrained shear strength were normalized based on the vertical effective stress, $\sigma_{v}^{\prime}$, to obtain comparable values of normalized undrained shear strength.

Based on research carried out by Wrzesiński [41] in a torsional shear hollow cylinder apparatus, a relationship was proposed to evaluate undrained shear strength at any angle of principal stress rotation [45]. The proposed relationship differs from the commonly known equation proposed by Bishop [9], because undrained shear strengths at $\alpha$ values of $0^{\circ}$ and $90^{\circ}$ are determined based on strength tests. This allows a more accurate determination of undrained shear strength for $\alpha$ values between $0^{\circ}$ and $90^{\circ}$.

The undrained shear strength at any angle of principal stress rotation, $\tau_{f u}^{\alpha}$, can be evaluated as [45]:

$$
\tau_{f u}^{\alpha}=\tau_{f u}^{90^{\circ}}+\eta_{\tau_{f u}}\left(\tau_{f u}^{0^{\circ}}-\tau_{f u}^{90^{\circ}}\right),
$$

where $\eta_{\tau_{f u}}$ is the index of change in undrained shear strength, $\tau_{f u}^{90^{\circ}}$ is the undrained shear strength at $\alpha=90^{\circ}$, and $\tau_{f u}^{0^{\circ}}$ is the undrained shear strength at $\alpha=0^{\circ}$.

The index of change in undrained shear strength due to a change in angle of principal stress rotation is defined as:

$$
\eta_{\tau_{f u}}=\left(\tau_{f u}^{\alpha}-\tau_{f u}^{90^{\circ}}\right) /\left(\tau_{f u}^{0^{\circ}}-\tau_{f u}^{90^{\circ}}\right) .
$$


Based on the TSHC test results, the following relationship between the indexes of change in undrained shear strength at any angle, $\alpha$, was proposed by Wrzesiński [41]:

$$
\eta_{\tau_{f u}}=1-(\sin \alpha)^{\exp \left[a_{0}+a_{1}\left(\frac{\alpha}{90^{\circ}}\right)^{n}\right]}
$$

where $a_{0}, a_{1}$, and $n$ are empirical coefficients.

The obtained relationship in Equation (5) for over-consolidated clayey sand (clSa(R)), tested by Kiziewicz [40], is presented in Figure 4. The coefficient of determination, $R^{2}$, for the relationship determining the change in undrained shear strength for clayey sand was equal to 0.93 . The values of empirical coefficients $a_{0}, a_{1}$, and $n$ for all tested soils are shown in Table 2. Test results showed that the values of empirical coefficients in Equation (5) depended on the type and structure of the soil, and its stress history. The proposed equation was derived on the basis of tests performed on over-consolidated clays with a low impact of glaciotectonic disturbances on the soil structure.

Figure 5 presents the undrained shear strength of clayey sand, clSa(R), based on Equation (3), with the index $\eta_{\tau_{f u}}$ obtained from Equation (5), and empirical coefficients presented in Table 2. In Figure 5, undrained shear strength evaluated based on Bishop's relationship is also presented. The undrained shear strength at $\alpha=90^{\circ}$ determined in the TSHC test was different from the result based on Bishop's relationship. In this case, the relative error was equal to 0.82. Using Bishop's relationship to determine undrained shear strength for clayey sand $\mathrm{clSa}(\mathrm{R})$, the biggest relative error was at an $\alpha$ value of $30^{\circ}$, and was equal to $4.19 \%$. However, when using the proposed method, the error was equal to $0.38 \%$.

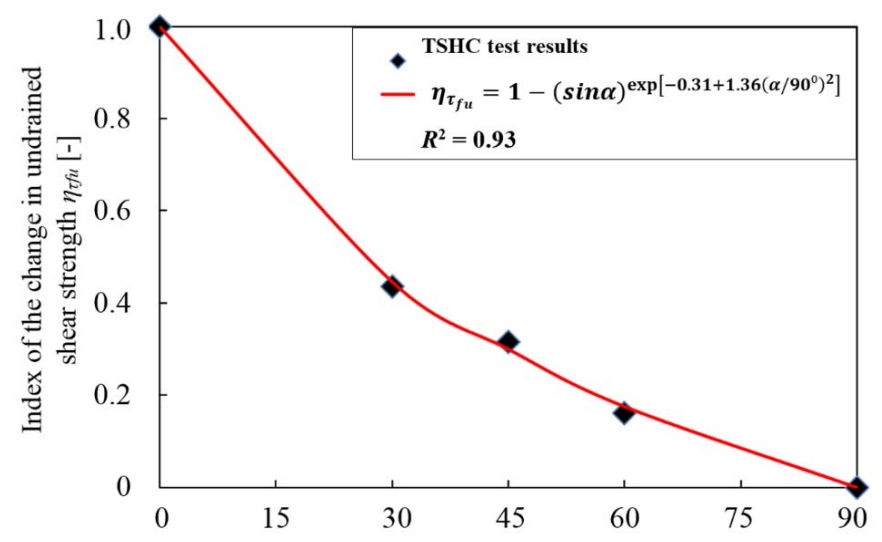

Figure 4. Relationship describing the index of change in undrained shear strength for clayey sand $\mathrm{clSa}(\mathrm{R})$.
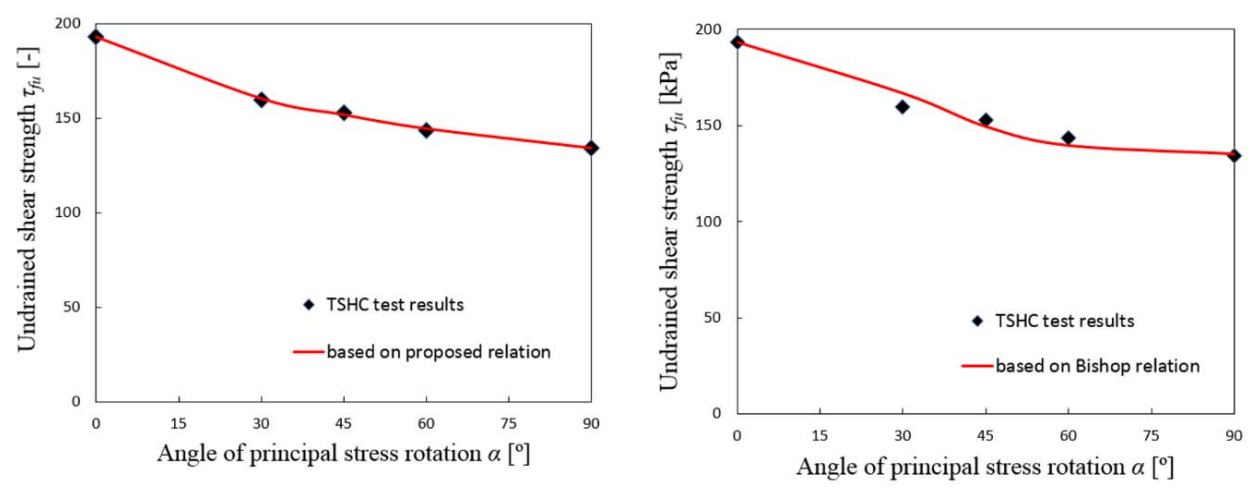

Figure 5. Undrained shear strengths based on Equation (3), Equation (5), and Bishop's relation for clayey sand $\mathrm{clSa}(\mathrm{R})$. 
Table 2. Results of the TSHC tests for clay (Cl), sandy silty clay (sasiCl), and clayey sand (clSa), as well as empirical coefficients for Equation (5) [40,41,45].

\begin{tabular}{|c|c|c|c|c|c|c|c|c|c|}
\hline \multirow{2}{*}{ Soil Type $\left(X_{1}\right)$} & \multirow{2}{*}{$\begin{array}{l}\text { Over-Consolidation } \\
\text { Ratio OCR }(-)\left(X_{2}\right)\end{array}$} & \multirow{2}{*}{$\begin{array}{l}\text { Plasticity Index } I_{P} \\
(\%)\left(X_{3}\right)\end{array}$} & \multirow{2}{*}{$\begin{array}{l}\text { Angle of the Principal } \\
\text { Stress Rotation } \alpha\left(^{\circ}\right)\left(X_{4}\right)\end{array}$} & \multirow{2}{*}{$\begin{array}{l}\text { Undrained Shear } \\
\text { Strength } \tau_{f u}(\mathrm{kPa})\end{array}$} & \multirow{2}{*}{$\begin{array}{l}\text { Effective Vertical } \\
\text { Stress } \sigma_{v}^{\prime}(\mathrm{kPa})\end{array}$} & \multirow{2}{*}{$\begin{array}{l}\text { Normalized Undrained Shear } \\
\text { Strength } \tau_{f u} / \sigma_{v o}^{\prime}(-)(Y)\end{array}$} & \multicolumn{3}{|c|}{ Coefficients of Equation (5) } \\
\hline & & & & & & & $a_{o}$ & $a_{1}$ & $n$ \\
\hline \multirow{5}{*}{$\mathrm{Cl}(\mathrm{U})$} & \multirow{5}{*}{3.5} & \multirow{5}{*}{77.6} & 0 & 228.5 & \multirow{5}{*}{310} & 0.737 & \multirow{5}{*}{0.34} & \multirow{5}{*}{-0.80} & \multirow{5}{*}{2} \\
\hline & & & 30 & 201.8 & & 0.651 & & & \\
\hline & & & 45 & 178.5 & & 0.576 & & & \\
\hline & & & 60 & 172.4 & & 0.556 & & & \\
\hline & & & 90 & 160.1 & & 0.516 & & & \\
\hline \multirow{7}{*}{$\operatorname{sasiCl}(\mathrm{U})$} & \multirow{7}{*}{2.7} & \multirow{7}{*}{34.7} & 0 & 129.3 & \multirow{7}{*}{220} & 0.588 & \multirow{7}{*}{0.52} & \multirow{7}{*}{-2.14} & \multirow{7}{*}{2} \\
\hline & & & 15 & 125.8 & & 0.572 & & & \\
\hline & & & 30 & 117.7 & & 0.535 & & & \\
\hline & & & 45 & 106.6 & & 0.485 & & & \\
\hline & & & 60 & 101.4 & & 0.461 & & & \\
\hline & & & 75 & 99.8 & & 0.454 & & & \\
\hline & & & 90 & 98.4 & & 0.447 & & & \\
\hline \multirow{7}{*}{ sasiCl(R) } & \multirow{7}{*}{2.7} & \multirow{7}{*}{34.7} & 0 & 118.7 & \multirow{7}{*}{220} & 0.54 & \multirow{7}{*}{0.64} & \multirow{7}{*}{-0.20} & \multirow{7}{*}{2} \\
\hline & & & 15 & 117.5 & & 0.534 & & & \\
\hline & & & 30 & 115.2 & & 0.524 & & & \\
\hline & & & 45 & 110.6 & & 0.503 & & & \\
\hline & & & 60 & 107.4 & & 0.488 & & & \\
\hline & & & 75 & 105.5 & & 0.48 & & & \\
\hline & & & 90 & 104.2 & & 0.478 & & & \\
\hline \multirow{5}{*}{$\mathrm{clSa}(\mathrm{R})$} & \multirow{5}{*}{8} & & 0 & 193.2 & & 2.415 & & & \\
\hline & & & 30 & 159.9 & & 1.999 & & & \\
\hline & & 10.5 & 45 & 152.7 & 80 & 1.909 & -0.31 & 1.36 & 2 \\
\hline & & & 60 & 143.6 & & 1.795 & & & \\
\hline & & & 90 & 134.1 & & 1.676 & & & \\
\hline
\end{tabular}




\section{Artificial Neural Network Analysis}

\subsection{Architecture of the Artificial Neural Network}

The class of neural network used in this study was a multilayer perceptron (MLP) with one hidden layer. The architecture of the network's $N-H-M$ type is defined by the number of nodes, $N$, in the input layer $X_{1}-X_{N}$; the number of nodes, $H$, in the hidden layer; and the number of nodes, $M=Y$, in the output layer.

Neural networks were constructed according to the criterion of minimization of the error function, which was the sum of squares of differences $(S O S)$ ), expressed by the following formula (for one output):

$$
E_{S O S}=\sum_{i=1}^{P}\left(d_{i}-y_{i}\right)^{2}
$$

where $P$ is the number of cases of set $P, i \in\{1, \ldots, P\}, d_{i}$ represents the known values of the tests, and $y_{i}$ corresponds to values predicted from neural networks.

Measures of errors were calculated separately for each subset: learning, $L$, testing, $T$, and validation, $V$. To assess the predictive quality of the neural network, values of error measures in the testing subset, $T$, were taken into account. Selected error measures for neural networks with one output are given by the following formulae:

- Relative error (for individual cases):

$$
R E_{i}=\left|\frac{d_{i}-y_{i}}{d_{i}}\right| \cdot 100 \%
$$

- Determination coefficient, $R^{2}$ :

$$
R^{2}=\frac{\sum_{i=1}^{P}\left(y_{i}-\bar{d}_{i}\right)^{2}}{\sum_{i=1}^{P}\left(d_{i}-\bar{d}_{i}\right)^{2}}
$$

- Mean absolute error:

$$
M A E=\frac{\sum_{i=1}^{P}\left|d_{i}-y_{i}\right|}{P}
$$

- $\quad$ Root mean squared error:

$$
R M S=\sqrt{\frac{1}{P} \cdot \sum_{i=1}^{P}\left(d_{i}-y_{i}\right)^{2}},
$$

where $d_{i}$ is the measured value, $y_{\mathrm{i}}$ is the value predicted by the neural network, $\bar{d}_{i}$ is the measured mean value in a given subset, and denotes the case number from subsets $L, T$, or $V$ with cardinality $P$, where $i \in\{1, \ldots, P\}$.

\subsection{Datasets}

Two datasets were used in the ANN analysis. Set $A$ consisted of results of the TSHC tests, where $n_{A}$ was equal to 24 cases, described by the following five variables: $X_{1}=$ soil type $\in\{\mathrm{Cl}(\mathrm{U})$, $\operatorname{sasiCl}(\mathrm{U})$, sasiCl(R), $\mathrm{clSa}(\mathrm{R})\} X_{2}=$ over-consolidation ratio, $\mathrm{OCR} \in\{3.5,2.7,8.0\} ; X_{3}=$ plasticity index, $I_{P} \in\{77.6$, $34.7,10.5 \%\} ; X_{4}=$ angle of principal stress rotation, $\alpha \in\left\{0,30,45,60,90^{\circ}\right\}$ or $\left\{0,15,30,45,60,75,90^{\circ}\right\}$; $Y=$ normalized undrained shear strength, $\tau_{f u} / \sigma_{v}^{\prime}$ (Table 2 ). The variables used were selected based on statistical analysis [41]. Variable $X_{1}$ was treated as a quality (linguistic) variable. Variable $X_{1}$ required the introduction of as many input neurons as there were soils (i.e., four neurons) [46].

Set $B$ was a set of "artificial" data, and consisted of $n_{B}=340$ cases, described by independent variables $X_{1}-X_{3}$ shown in Table 2 , and dependent variable $Y$, representing normalized undrained 
sheer strength, $\tau_{f u} / \sigma^{\prime}{ }_{v}$, calculated from Equations (3) and (4) using empirical coefficients shown in Table 2 for the independent variable, $\alpha$, in the range $1-89^{\circ}$ in $1^{\circ}$ increments. Set $B$ was used to create and train the neural networks. The selected artificial neural network was used to predict $\tau_{f u} / \sigma_{v}^{\prime}$ values based on new, actual data from the TSHC tests in set $A$.

\subsection{Training and Testing}

Set $B$ was randomly assigned to $50 \%, 25 \%$, and $25 \%$ of the learning, $L$, testing, $T$, and validation, $V$ subsets, respectively. The testing subset was used to periodically check the generalizability acquired by the network, and the validation subset was used for the final evaluation of the trained neural network.

The predictive quality of the neural regression model was evaluated on the basis of error analysis, and calculated independently for the following subsets: learning, $L$, testing, $T$, and validation, $V$. Neural networks were optimized for the number of neurons in the hidden layer, the activation function in the neurons of the hidden and output layers, and the learning method. The conjugate gradient (CG) algorithm was chosen for network learning. An early-stopping method of training was used [47]. Learning was stopped after 35 learning cycles (epochs). Neural networks with the best predictive quality were determined on the basis of the highest values of the determination coefficient $\left(R^{2}\right)$, the lowest values of root mean squared errors (RMSs), and the lowest mean values of relative errors (REs) [47].

Based on the analysis of many neural networks, a neural network of 7-6-1 was selected, meaning seven input neurons, six neurons in one hidden layer, and one output neuron (Figure 6). Activation functions were identified. For the hidden neurons, this was a tanh sigmoid curve, and for the output neuron, this was a logistic function. The errors in the $L, T$, and $V$ subsets of dataset $B$ were small, while the determination coefficients $\left(R^{2}\right)$ were very high (Table 3$)$. The relative prediction error $(R E)$ of the proposed neural network had a maximum value of about $\pm 3 \%$ (Figure 7 ) in all subsets of dataset $B$.

Statistical analysis performed by Wrzesiński [41] indicated that, from linear regression models (simple and multiple), the highest value of the determination coefficient was 0.951 , and the lowest mean relative error was about $\pm 20 \%$.

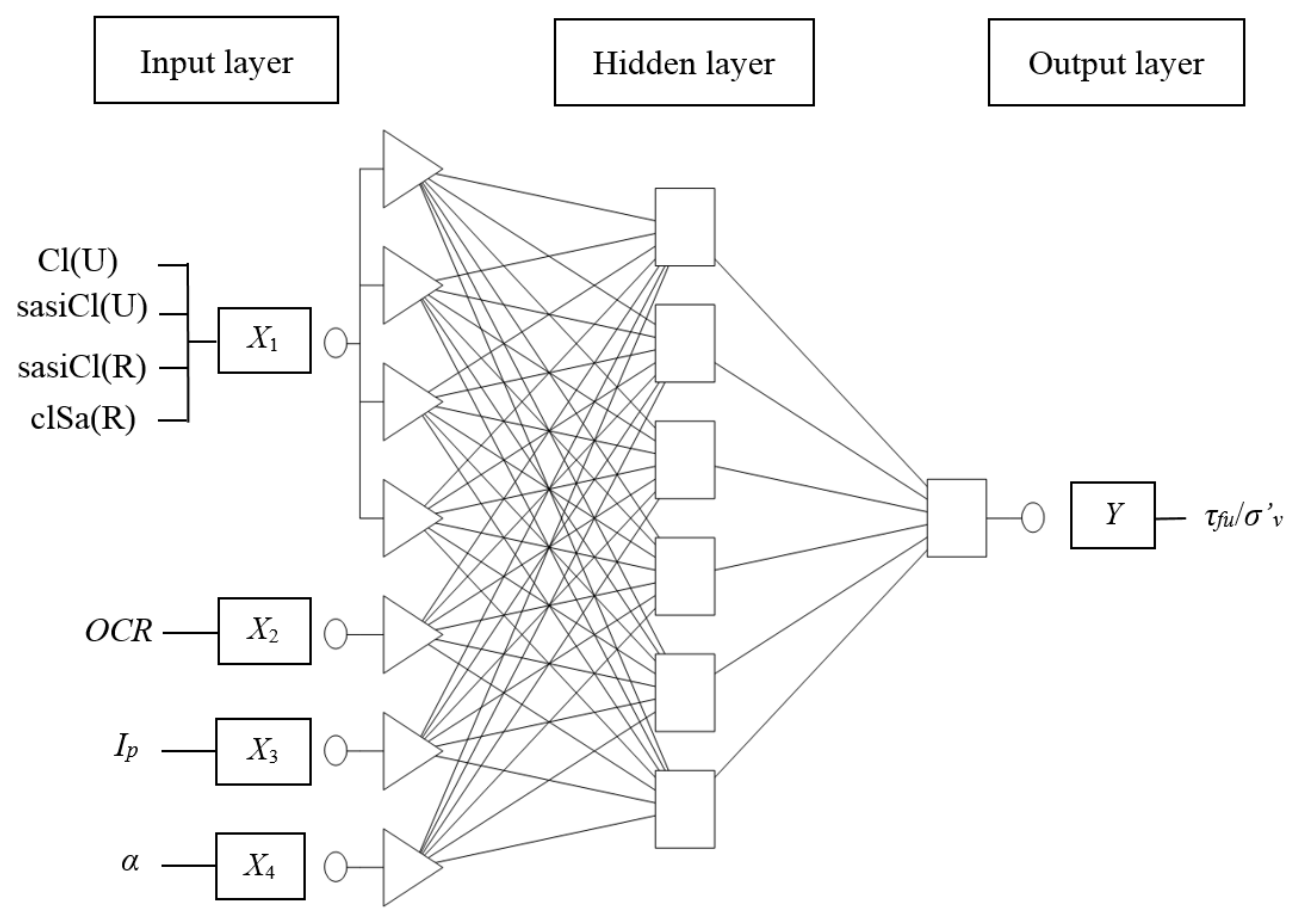

Figure 6. Architecture of the two-layer artificial neural network, 7-6-1 conjugate gradient (CG) 35 . 
Table 3. Measures of network errors in the 7-6-1 network of subsets $L, T$, and $V$ of set $B$. MAE: mean absolute error; $R^{2}$ : coefficient of determination; $R M S$ : root mean squared error.

\begin{tabular}{cccc}
\hline Measures of Errors & Subset learning, $\boldsymbol{L}$ & Subset testing, $\boldsymbol{J}$ & Subset validation, $\boldsymbol{V}$ \\
\hline$R M S$ & 0.0057 & 0.0054 & 0.0052 \\
$M A E$ & 0.0109 & 0.0110 & 0.0105 \\
$R^{2}$ & 0.998 & 0.998 & 0.998 \\
\hline
\end{tabular}

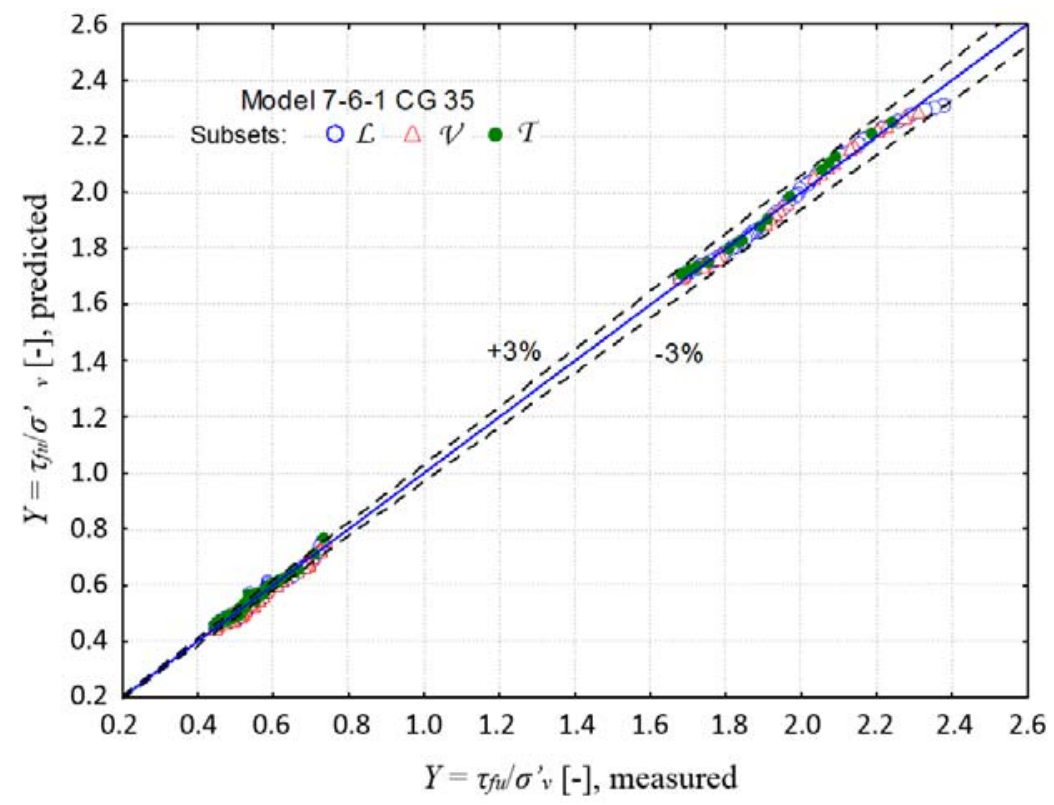

Figure 7. Comparison between measured values of independent variable $Y, \tau_{f u} / \sigma_{v}^{\prime}$, and values of $Y$ predicted by proposed neural network, 7-6-1, in set $B$.

\subsection{Neural Network Prediction}

The trained artificial neural network, 7-6-1, was tested by applying it to the prediction of $\tau_{f u} / \sigma_{v}^{\prime}$, based on laboratory data from set $A$. Independent variables $X_{1}, X_{2}, X_{3}$, and $X_{4}$ (Table 2) were introduced into the network, and $\tau_{f u} / \sigma_{v}^{\prime}$ values predicted by the network were obtained. A comparison between measured values of $\tau_{f u} / \sigma_{v}^{\prime}$ obtained from the TSHC tests and values of $\tau_{f u} / \sigma_{v}^{\prime}$ predicted using the proposed neural network 7-6-1 are shown in Table 4 . The single maximum value of relative error was about $6 \%$.

Table 4. Comparison between measured values of $\tau_{f u} / \sigma^{\prime} v$ obtained from the TSHC tests and values of $\tau_{f u} / \sigma_{v}^{\prime}$ predicted using the proposed neural network 7-6-1, in set $A$.

\begin{tabular}{cccc}
\hline No. & $\begin{array}{c}\text { Measured Values } \\
\boldsymbol{\tau}_{f u} / \sigma_{v}^{\prime}{ }_{v} \text { from Set A } \boldsymbol{d}_{\boldsymbol{i}} \mathbf{( - )}\end{array}$ & $\begin{array}{c}\text { Predicted Values } \boldsymbol{\tau}_{f u} / \sigma_{v}^{\prime} \text { Based } \\
\text { on 7-6-1 Network } \boldsymbol{y}_{\boldsymbol{i}}(\mathbf{-})\end{array}$ & $\begin{array}{c}\text { Relative Errors of } \\
\text { Individual Case } \boldsymbol{R} \boldsymbol{E}_{\boldsymbol{i}}(\mathbf{\%})\end{array}$ \\
\hline 1 & 0.737 & 0.775 & 5.16 \\
2 & 0.651 & 0.634 & 2.61 \\
3 & 0.576 & 0.59 & 2.43 \\
4 & 0.556 & 0.554 & 0.36 \\
5 & 0.516 & 0.512 & 0.77 \\
6 & 0.588 & 0.612 & 4.08 \\
7 & 0.572 & 0.558 & 2.45 \\
8 & 0.535 & 0.52 & 2.8 \\
9 & 0.485 & 0.491 & 1.24 \\
10 & 0.461 & 0.468 & 1.52 \\
11 & 0.454 & 0.455 & 0.22 \\
\hline
\end{tabular}


Table 4. Cont.

\begin{tabular}{cccc}
\hline No. & $\begin{array}{c}\text { Measured Values } \\
\boldsymbol{\tau}_{f u} / \boldsymbol{\sigma}^{\prime}{ }_{\boldsymbol{v}} \text { from Set } \mathbf{A} \boldsymbol{d}_{\boldsymbol{i}} \mathbf{( - )}\end{array}$ & $\begin{array}{c}\text { Predicted Values } \boldsymbol{\tau}_{\boldsymbol{f u}} / \boldsymbol{\sigma}_{\boldsymbol{v}}{ }_{\boldsymbol{v}} \text { Based } \\
\text { on 7-6-1 Network } \boldsymbol{y}_{\boldsymbol{i}} \mathbf{( - )}\end{array}$ & $\begin{array}{c}\text { Relative Errors of } \\
\text { Individual Case } \boldsymbol{R} \boldsymbol{E}_{\boldsymbol{i}}(\mathbf{\%})\end{array}$ \\
\hline 12 & 0.447 & 0.452 & 1.12 \\
13 & 0.54 & 0.572 & 5.92 \\
14 & 0.534 & 0.531 & 0.56 \\
15 & 0.524 & 0.5 & 4.58 \\
16 & 0.503 & 0.48 & 4.57 \\
17 & 0.488 & 0.47 & 3.69 \\
18 & 0.48 & 0.47 & 2.08 \\
19 & 0.478 & 0.478 & 0 \\
20 & 2.415 & 2.322 & 3.85 \\
21 & 1.999 & 2.019 & 1 \\
22 & 1.909 & 1.885 & 1.26 \\
23 & 1.795 & 1.789 & 0.33 \\
24 & 1.676 & 1.694 & 1.07 \\
\hline
\end{tabular}

\section{Conclusions}

The presented neural network, with the architecture 7-6-1, predicted the real value of the variable, $\tau_{f u} / \sigma_{v}^{\prime}$, based on the following data: soil type, over-consolidation ratio (OCR), plasticity index $\left(I_{P}\right)$, and angle of principal stress rotation $(\alpha)$ for tested pre-consolidated cohesive soils.

The 7-6-1 artificial neural network was selected with a determination coefficient of 0.998 and a mean relative error of around $\pm 3 \%$ in set $B$, and the single maximum relative error was about $6 \%$. It had better predictive quality of normalized undrained shear strength $\left(\tau_{f u} / \sigma_{v}^{\prime}\right)$ than linear regression models, where the highest determination coefficient was 0.951 , and the lowest mean relative error was about $\pm 20 \%$.

Conclusions from the analysis only concern the tested types of cohesive soils. As further tests are carried out in the torsional shear hollow cylinder apparatus, the ANN models can be upgraded and extended, taking into account other soil types, and possibly generalizing for most types of cohesive soils.

Author Contributions: G.W. and Z.L. prepared research program, performed laboratory tests and prepared the manuscript. M.J.S. performed Artificial Neural Network analysis and prepared the manuscript.

Acknowledgments: This work, carried out in 2017-2018 at the Warsaw University of Life Sciences-SGGW and the Bialystok University of Technology, was supported by Polish financial resources on science.

Conflicts of Interest: The authors declare no conflict of interest.

\section{References}

1. Jardine, R.J. One perspective of the pre-failure deformation characteristics of some geomaterials. Pre-failure Deformation of Geomaterials. Proc. Sapporo. Balkema Rotterdam. 1995, 2, 855-885.

2. Lipiński, M.J.; Wdowska, M.K. A stress history and strain dependent stiffness of overconsolidated cohesive soil. Ann. Warsaw Univ. Life Sci.-SGGW Land Reclam. 2011, 43, 207-216. [CrossRef]

3. Hight, D.W.; Gens, A.; Symes, M.J. The development of a new hollow cylinder apparatus for investigating the effects of principal stress rotation in soils. Géotechnique 1983, 33, 335-383. [CrossRef]

4. Lade, V.P.; Kirkgard, M.M. Effects of stress rotation and changes of b-values on cross-anisotropic behavior of natural $\mathrm{K}_{\mathrm{o}}$ consolidated soft clay. Soils Found. 2000, 40, 93-105. [CrossRef]

5. Lin, H.; Penumadu, D. Experimental investigation on principal stress rotation in Kaolin Clay. J. Geotech. Geoenviron. Eng. 2005, 131, 633-642. [CrossRef]

6. Nishimura, S.; Minh, N.A.; Jardine, R.J. Shear strength anisotropy of natural London Clay. Géotechnique 2007, 57, 49-62. [CrossRef] 
7. Rolo, R. The Anisotropic Stress-Strain-Strength Behavior of Brittle Sediments. Ph.D. Thesis, Imperial College, London, UK, 2003.

8. Zdravković, L.; Jardine, R.J. The effects on anisotropy of rotating the principal stress axes during consolidation. Géotechnique 2001, 51, 69-83. [CrossRef]

9. Bishop, A.W. The strength of soils as engineering materials. Géotechnique 1966, 16, 91-130. [CrossRef]

10. Kulhavy, F.H.; Mayne, P.W. Manual on Estimating Soil Properties for Foundation Design; Report EK-6800; Electric Power Research Institute: Palo Alto, CA, USA, 1990.

11. Ching, J.; Phoon, K.K. Multivariate distribution for undrained shear strength under various test procedures. Can. Geotech. J. 2013, 50, 907-923. [CrossRef]

12. Houlsby, N.M.T.; Houlsby, G.T. Statistical fitting of undrained strength data. Géotechnique 2013, 63, 1253-1263. [CrossRef]

13. Jang, D.; Park, H.; Choi, G. Estimation of Leakage Ratio Using Principal Component Analysis and Artificial Neural Network in Water Distribution Systems. Sustainability 2018, 10, 750. [CrossRef]

14. Kang, P.-S.; Lim, J.-S.; Huh, C. Artificial Neural Network Model to Estimate the Viscosity of Polymer Solutions for Enhanced Oil Recovery. Appl. Sci. 2016, 6, 188. [CrossRef]

15. Li, W.; Cui, L.; Zhang, Y.; Cai, Z.; Zhang, M.; Xu, W.; Zhao, X.; Lei, Y.; Pan, X.; Li, J.; et al. Using a Backpropagation Artificial Neural Network to Predict Nutrient Removal in Tidal Flow Constructed Wetlands. Water 2018, 10, 83. [CrossRef]

16. Zhu, X.; Fan, Y.; Zhang, F.; Ye, X.; Chen, C.; Yue, H. Multiple-Factor Based Sparse Urban Travel Time Prediction. Appl. Sci. 2018, 8, 279. [CrossRef]

17. Paez, T.L. Neural networks in mechanical systems simulation, identification and assessment. Shock Vibr. 1993, 1, 177-199. [CrossRef]

18. Adeli, H. Neural Networks in Civil Engineering: 1989-2000. Comput.-Aided Civ. Inf. 2001, 16, 126-142. [CrossRef]

19. Ghaboussi, J. Biologically inspired soft computing methods in structural mechanics and engineering. Struct. Eng. Mech. 2001, 11, 485-502. [CrossRef]

20. Rojas, R. Neural Networks: A Systematic Introduction; Springer: Berlin, Germany, 1996.

21. Waszczyszyn, Z. Advances of Soft Computing in Engineering; CISM Courses and Lectures; Springer: Wien, Austria; New York, NY, USA, 2010.

22. Waszczyszyn, Z. Artificial neural networks in civil engineering: another five years of research in Poland. Comp. Assist. Mech. Eng. Sci. 2011, 18, 131-146.

23. Rafiq, M.Y.; Bugmann, G.; Easterbrook, D.J. Neural network design for engineering applications. Comput. Struct. 2001, 79, 1541-1552. [CrossRef]

24. Dihoru, L.; Muir Wood, D.; Sadek, T.; Lings, M. A neural network for error prediction in true triaxial apparatus with flexible boundaries. Comput. Geotech. 2005, 32, 59-71. [CrossRef]

25. Pichler, B.; Lackner, R.; Mang, H.A. Back analysis of model parameters in geotechnical engineering by means of soft computing. Int. J. Numer. Meth. Eng. 2003, 57, 1943-1978. [CrossRef]

26. Shahin, M.A.; Jaksa, M.B.; Maier, H.R. Artificial Neural Network applications in geotechnical engineering. Aust. Geomechan. 2001, 36, 49-62.

27. Shahin, M.A.; Jaksa, M.B.; Maier, H.R. State of the art of Artificial Neural Networks in geotechnical engineering. Elect. J. Geotech. Eng. 2008, 8, 1-26.

28. Tian, J.; Li, C.; Liu, J.; Yu, F.; Cheng, S.; Zhao, N.; Wan Jaafar, W.Z. Groundwater Depth Prediction Using Data-Driven Models with the Assistance of Gamma Test. Sustainability 2016, 8, 1076. [CrossRef]

29. Sulewska, M.J. Applying artificial neural networks for analysis of geotechnical problems. Comp. Assist. Mech. Eng. Sci. 2011, 18, 231-241.

30. Zhou, T.; Wang, F.; Yang, Z. Comparative Analysis of ANN and SVM Models Combined with Wavelet Preprocess for Groundwater Depth Prediction. Water 2017, 9, 781. [CrossRef]

31. Basheer, I.A. Selection of methodology for neural network modeling of constitutive hysteresis behavior of soils. Comput.-Aided Civ. Inf. 2000, 15, 440-458. [CrossRef]

32. Ellis, G.W.; Yao, C.; Zhao, R.; Penumadu, D. Stress-strain modeling of sands using artificial neural network. J. Geotech. Eng. 1995, 121, 429-435. [CrossRef]

33. Fu, Q.; Hashash, Y.M.A.; Hung, S.; Ghaboussi, J. Integration of laboratory testing and constitutive modeling of soils. Comput. Geotech. 2007, 34, 330-345. [CrossRef] 
34. Najjar, Y.M.; Huang, C. Simulating the stress-strain behavior of Georgia kaolin via recurrent neuronet approach. Comput. Geotech. 2007, 34, 346-361. [CrossRef]

35. Penumadu, D.; Zhao, R. Triaxial compression behavior of sand and gravel using artificial neural networks (ANN). Comput. Geotech. 1999, 24, 207-230. [CrossRef]

36. Sidarta, D.E.; Ghaboussi, J. Constitutive modeling of geomaterials from non-uniform material test. Comput. Geotech. 1998, 22, 53-71. [CrossRef]

37. Lee, S.J.; Lee, S.R.; Kim, Y.S. An approach to estimate unsaturated shear strength using artificial neural network and hyperbolic formulation. Comput. Geotech. 2003, 30, 489-503. [CrossRef]

38. Das, S.K.; Basudhar, P.K. Undrained lateral load capacity of piles in clay using artificial neural network. Comput. Geotech. 2006, 33, 454-459. [CrossRef]

39. Byeon, W.Y.; Lee, S.R.; Kim, Y.S. Application of flat DMT and ANN to Korean soft clay deposits for reliable estimation of undrained shear strength. Int. J. Offshore Pol. Eng. 2006, 16, 73-80.

40. Kiziewicz, D. Evaluation of Shear Strength of Cohesive Soils with Use of Non-Standard Stress Path. Ph.D. Thesis, Warsaw University of Life Sciences, Warsaw, Poland, 2012.

41. Wrzesiński, G. Stability Analysis of an Embankment with Influence of Principal Stress Rotation on the Shear Strength of Subsoil. Ph.D. Thesis, Warsaw University of Life Sciences, Warsaw, Poland, 2016.

42. EN ISO 14688-1. Geotechnical Investigation and Testing-Identification and Classification of Soil-Part 1: Identification and Description; International Organization for Standardization: Geneva, Switzerland, 2002.

43. EN ISO 14688-2. Geotechnical Investigation and Testing_Identification and Classification of Soil_Part 2: Principles for a Classification; International Organization for Standardization: Geneva, Switzerland, 2004.

44. Wrzesiński, G.; Lechowicz, Z. Influence of the rotation of principal stress directions on undrained shear strength. Ann. Warsaw Univ. Life Sci.-SGGW Land Reclam. 2013, 45, 183-192. [CrossRef]

45. Wrzesiński, G.; Lechowicz, Z. Testing of undrained shear strength in a Hollow Cylinder Apparatus. Studia Geotechnica et Mechanica 2015, 37, 69-73. [CrossRef]

46. Masters, T. Practical Neural Network Recipes in C++; Academic Press: New York, NY, USA, 1993.

47. Bishop, C.M. Neural Networks for Pattern Recognition; Oxford University Press: Oxford, UK, 1995.

(C) 2018 by the authors. Licensee MDPI, Basel, Switzerland. This article is an open access article distributed under the terms and conditions of the Creative Commons Attribution (CC BY) license (http:/ / creativecommons.org/licenses/by/4.0/). 